\title{
Methods of Assessment of Cryopreserved Semen
}

\author{
Agnieszka Partyka, Wojciech Niżański and Małgorzata Ochota \\ Wroclaw University of Environmental and Life Sciences \\ Poland
}

\section{Introduction}

The numerous effects that cryopreservation can induce in spermatozoa, ranging from lethal injuries to those which merely impair their subsequent function. In the last few years, the considerable increase in our understanding of both, the cell physiology of spermatozoa, and the stress of cryopreservation, have contributed to a renewed interest in improving the performance of cryopreserved semen.

Despite the significant progress, the post-thaw viability and fertility of the cryopreserved sperm are still reduced, as a consequence of accumulated cellular injuries that arise throughout the cryopreservation process. Many laboratory tests have already been carried out to verify these detrimental effects and their origin. Their is needed to well understand the whole process of cryopreservation and its influence on sperm function. As a consequence, it would lead to a subsequent improvement of sperm viability by means of reformulated protocols and approaches helping to minimize the detrimental effect of cryopreservation.

Here, we present an overview of the cryopreserved semen assessment methods in the light of sperm physiology, in order to relate these factors to altered functions of cryopreserved sperm and to determine the fertilizing potential of the frozen-thawed semen.

\section{Conventional methods of semen assessment}

Light microscopy is the most often used to analyze the quality and predict the fertility of the cryopreserved semen in the conventional way. Visual assessment requires such equipment as microscope, heated stage and slides, as well as an experienced evaluator, however the assessment is subjected to the evaluator bias.

\subsection{Sperm motility}

Motility is one of the most important features of a fertile spermatozoa. It was the first, and continues to be the most widely used indicator of sperm function. Sperm motility is an important attribute, because it is readily identifiable and reflects several structural, and functional competence, as well as essential aspects of spermatozoa metabolism. Sperm motility is expressed as the percentage of total motile or progressively motile spermatozoa. This parameter is usually assessed by the subjective visual examination under a phase contrast microscope at $37^{\circ} \mathrm{C}$ using low objectives (10 or 20x). Light microscopic evaluation 
of motile spermatozoa does not require expensive equipment, is a simple and rapid method for assessment of sperm quality, however, it is a highly subjective and not reliable assay for the prediction of fertility (Peña Martínez, 2004).

\subsection{Sperm morphology}

On account of the fact that freezing and thawing process provokes morphological or biochemical cryogenic damage resulting in sperm dysfunction and changes in cell's membrane, the sperm morphology evaluation is an essential component of any semen analysis and provides the clinical information about the potential fertility of semen sample.

Despite, there are many different and also new methods, as described below, used in semen analysis, semen smears are still employed for routine light microscopic morphological evaluation. However, this assessment is subjective and results are largely dependent on the proficiency and experience of the evaluator. Vital dye in combination with different stains for acrosome evaluation are commonly utilised to assess the spermatozoa morphology and the viability together. For this purpose, India ink, William's, Karras, Spermac, Diff-Quick, Papanicolaou, Fuelgen or combination: Trypan blue and Giemsa, Trypan blue, Bismarck Brown and Rose Bengal, and finally eosin-nigrosin (described in 2.3 section) have been used in birds and mammals including human (Brito et al., 2003; Brito et al., 2011; Didion et al., 1989; Freneau et al., 2010; Łukaszewicz et al., 2008; Partyka et al., 2007; Rodriguez-Gil et al., 1994; Sprecher \& Coe, 1996; Talbot \& Chacon, 1981). In spite of that, Freneau et al. (2010) have shown that differential interference phase contrast microscopy of wet-mounted semen is the superior method for bulls sperm morphology assessment. For cats sperm morphology, the best differentiation of sperm structures, especially acrosome, with lower artifacts, fast green FCF-rose Bengal staining or Hancock and Glendhill solution staining and phasecontrast microscope are encouraged (Zambelli \& Cunto, 2006). However, when frozenthawed semen is analyzed these stains are negatively affected by egg yolk and glycerol, causing egg yolk agglutination and lack of sperm structures differentiation. Therefore, sperm washing is recommended to prevent these interferences (Zambelli \& Cunto, 2006).

Many reports have shown the common classification system for the morphology of spermatozoa from different species. However, classification categories are different for the various species and the adoption of uniform system within each species is needed. Mammalian spermatozoa abnormalities can be divided into primary and secondary abnormalities (Blom, 1950), or in some classification systems into major and minor abnormalities (Blom, 1968, 1983). Primary sperm defects are assumed to have occurred during spermatogenesis, and secondary defects are assumed to have occurred during maturation in the epididymis and the transit through the ductal system and specimen preparation. Second system classifies sperm defects according to the perceived effects on fertility. The most common sperm abnormalities (Fig. 1) are related to abnormal acrosomal regions/heads, detached head, proximal droplets, distal droplets, abnormal midpieces, bent/coiled tails. Acrosome defects include knobbed, roughed, and detached acrosomes. Head defects include microcephalic, macrocephalic, pyriform, tapered, other shape defects, nuclear vacuoles, and multiple heads. Midpiece and principal piece (tail) abnormalities enclose simple bent, folded, fractured, thickened, swollen, roughed, Dag-like, disrupted sheet, duplicated, coiled. Various defects are typical for each species.

For each slide, at least 100-300 spermatozoa should be counted at 400-1000x magnification, which allows for accurate calculation of the percentage of different sperm defects. 

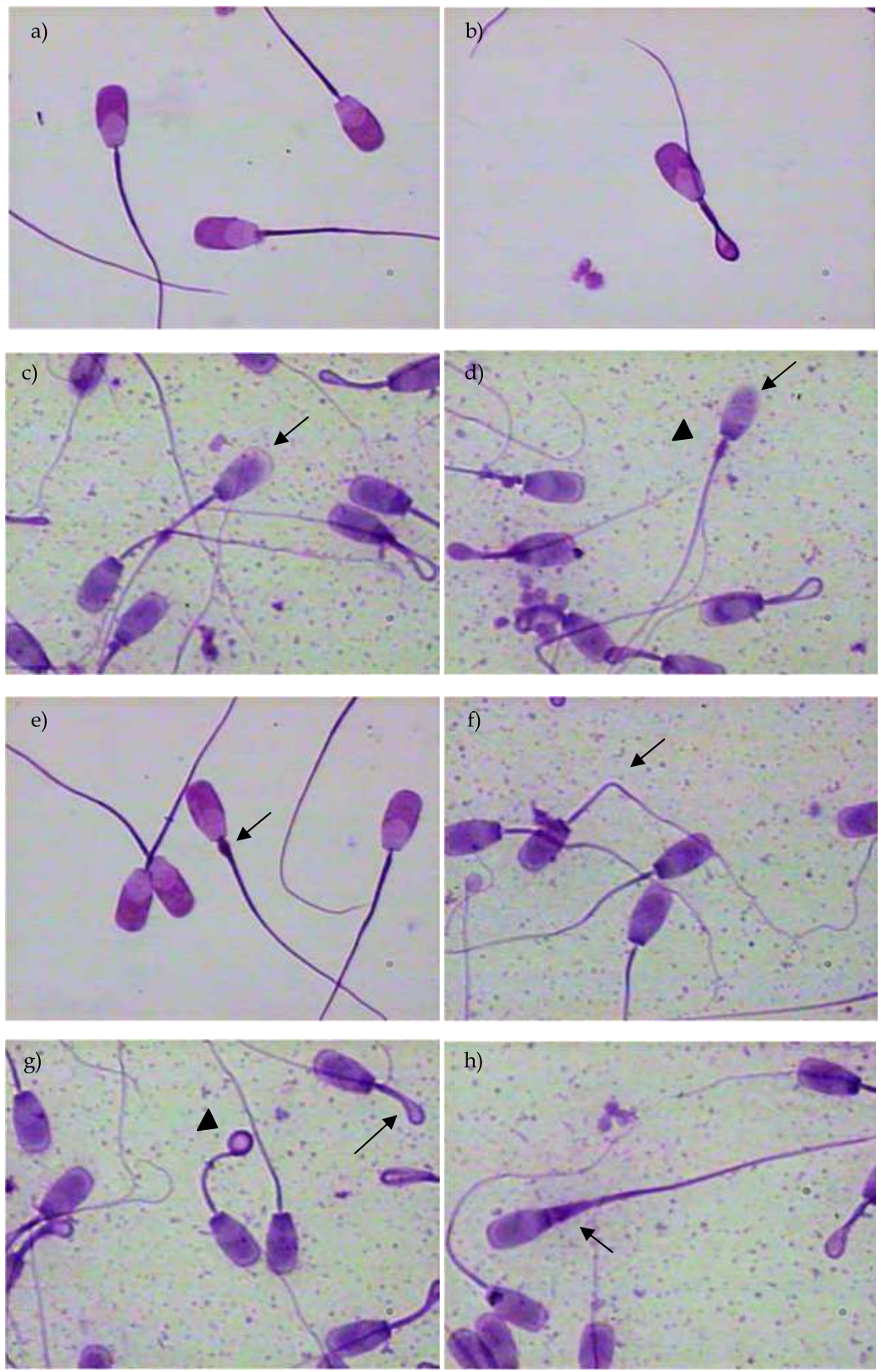

Fig. 1. Selected defects in sperm morphology (boar spermatozoa): a) normal sperm cells; b) looped tail; c) acrosome detachment; d) loss of acrosomal contents (back arrow), proximal cytoplasmatic droplet (arrowhead); e) proximal cytoplasmatic droplet; f) kinked midpiece; g) looped tail (black arrow), coiled tail (arrowhead); h) thickened midpiece. 


\subsection{Sperm membrane integrity}

Live-dead staining. The traditional method for assessing whether the sperm membrane is intact or disrupted involves examining a percentage of viable sperm by a stain exclusion assay. For the determination of cell viability live-dead stains as aniline-eosin, eosin-nigrosin or eosin-fast green are widely used. Integrity of the plasma membrane is shown by the ability of a viable cell to exclude the dye, whereas the dye will diffuse passively into sperm cells with damaged plasma membranes. When stained smears are viewed under the oil immersion objective of light microscope, the percentage of viable, live, properly formed spermatozoa, nonviable and also partially-damaged spermatozoa can be determined. In eosin-nigrosin stain under the microscope, live spermatozoa appear white, unstained against the purple background of nigrosin (Fig. 2a). Dead and damaged spermatozoa which have a permeable plasma membrane are pink (Fig. 2b). The evaluation of the percentage of live and dead spermatozoa and the percentage of morphology defects may be performed on the same nigrosin-eosin stained slides.

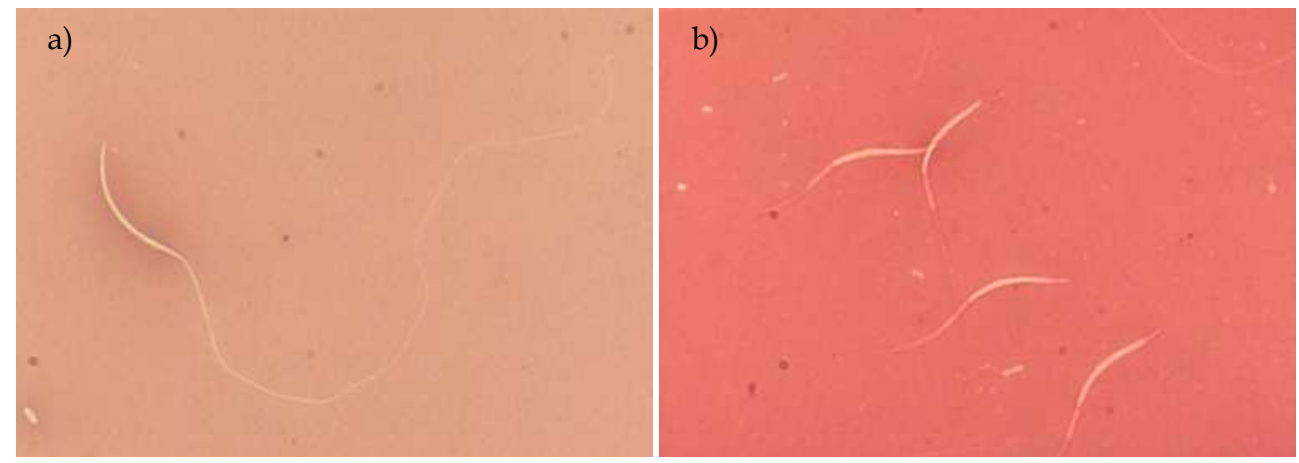

Fig. 2. Eosin-nigrosin staining for live-dead cells (chicken spermatozoa): a) live spermatozoon, b) dead spermatozoa.

The hypoosmotic swelling test (HOS) is a method of investigating membrane integrity in sperm and, as such, is an alternative to supra-vital staining. In fact, the HOS test is thought to have the advantage of indicating not only whether the membrane is intact, but also whether it is osmotically active. Sperm with an intact, functional membrane when are exposed to an hypoosmotic solution incubated for 30 minutes at $37^{\circ} \mathrm{C}$, swell to achieve an osmotic equilibrium. An expression of this is a typical swelling of the sperm tail (Fig. 3) (Neild et al., 1999). The HOS test is a simple, inexpensive and easily applicable technique, which has been adapted to assess spermatozoa of several species (Corea \& Zavos, 1994; Kumi-Diaka, 1993 Neild et al., 1999; Pérez-Llano et al., 2001; Santiago-Moreno et al., 2009). It has been suggested that this test may supplement the information provided by the conventional parameters of semen analysis, and is useful for fertilizing ability assessment (Brito et al., 2003; Vazquez et al., 1997). This test correlates highly with other predictive tests, such as hamster oocyte penetration (Jeyendran et al., 1992), in-vitro fertilization (IVF) results in human (van der Venn et al., 1986), and with pregnancy rates in pigs (Pérez-Llano et al., 2001). The HOS test seems to be more appropriate for predicting the fertilizing capacity of frozen-thawed than fresh semen, because membrane damage is here a more important limiting factor than in the former (Colenbrander et al., 2003). 


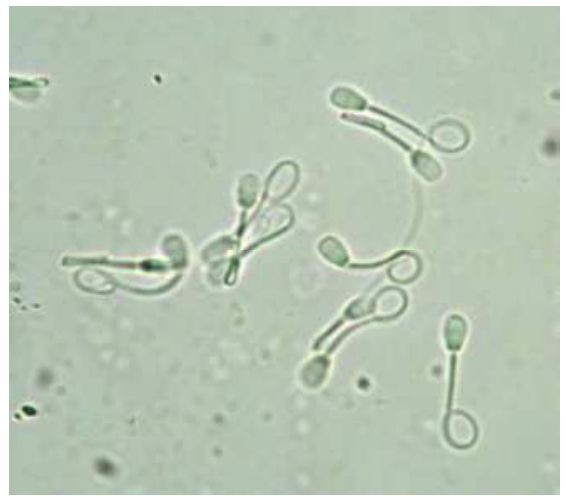

Fig. 3. HOS test (canine spermatozoa).

\section{Advanced methods of semen assessment}

\subsection{Computer assisted sperm analysis (CASA)}

Recently, computer assisted sperm analysis has been introduced to veterinary andrology, same as it has been used in reproductive technologies in human andrology (Rijsselaere et al., 2003; Verstegen et al., 2002). This technique assures objective semen assessment, whereas the main disadvantage of conventional semen evaluation is variability of obtained results. Subjectivity of traditional semen analysis is associated mainly with experience and skill of the observer, the method of specimen preparation, staining technique and number of cells evaluated. Variations in the results of conventional evaluation of the same semen samples by different observers and laboratories may achieve up to 30-60\% (Coetzee et al., 1999; Davis \& Katz, 1992). Subsequently, correlations between spermatozoa characteristics and fertility trials in females are relatively low. Computer assisted sperm analysers allow for calculation of several motility parameters, which characterize movement of individual sperm cells. They include VAP-average path velocity, VSL-straight line velocity, VCL-cell velocity, ALHamplitude of lateral head displacement, BCF-beat cross frequency (Fig. 4), STR-straightness of cell track, LIN-linearity of cell track, subpopulation of rapid, medium and slow cells (Niżański et al., 2009). Selected characteristics of spermatozoa motility parameters measured by CASA systems are summarized in table 1.
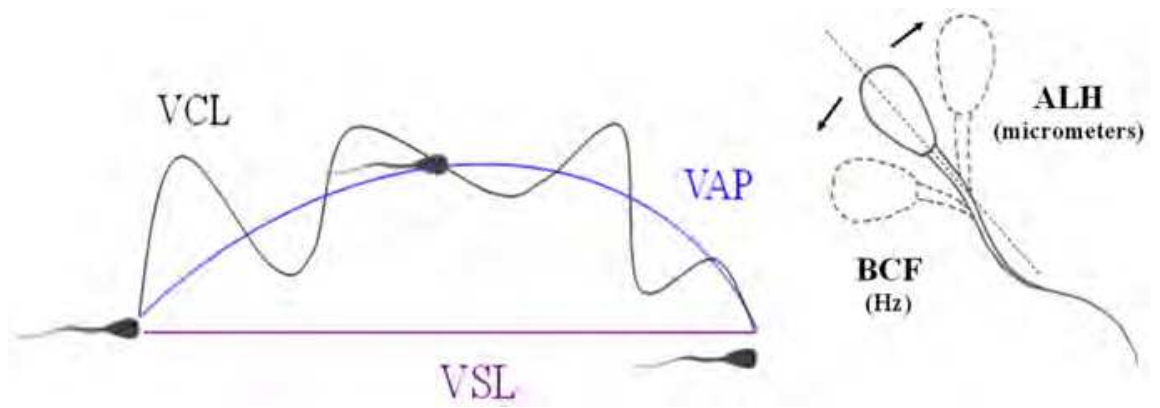

Fig. 4. Scheme of different velocities and parameters of sperm movement measured by CASA systems. 


\begin{tabular}{lll}
\hline Parameter & Unit & Description \\
\hline MOT & $\%$ & $\begin{array}{l}\text { Motility - The population of cells that are moving at or above a } \\
\text { minimum speed as determined by values defined under setup. }\end{array}$ \\
\hline PMOT & $\%$ & $\begin{array}{l}\text { Progressive motility- the population of cells that are moving actively } \\
\text { forward. }\end{array}$ \\
\hline VCL & $\mu \mathrm{m} / \mathrm{s}$ & $\begin{array}{l}\text { Track speed - Is defined as average velocity measured over the actual } \\
\text { point-to-point track followed by the cell. }\end{array}$ \\
\hline VSL & $\mu \mathrm{m} / \mathrm{s}$ & $\begin{array}{l}\text { Path velocity - Is defined as average velocity over smoothed average } \\
\text { position of the cell. }\end{array}$ \\
\hline ALH & $\mu \mathrm{m}$ & $\begin{array}{l}\text { Progressive velocity - Is measured in the straight line distance } \\
\text { between the beginning and the end of the track. }\end{array}$ \\
\hline BCF & Hz & $\begin{array}{l}\text { Amplitude of Lateral Head Displacement - is the mean width of the } \\
\text { head oscillation as the cell moves. }\end{array}$ \\
\hline moves back and forth in its track across the cell path.
\end{tabular}

Table 1. Selected parameters of spermatozoa motility measured by CASA systems.

It was proven in human, that results obtained with CASA systems are better correlated with the outcome of assisted reproductive techniques than results of traditional semen evaluation (Verstegen et al., 2002). Blesbois et al. (2008) showed that some of parameters detected in CASA system are correlated with fertility results obtained with frozen-thawed chicken spermatozoa (PMOT, PROG, VAP, VSL). Most of them were affected by cryopreservation, with the exception of straightness (STR), suggesting that cryopreservation slows down the movement of chicken spermatozoa without changing the shape of trajectories.

The important advantage of computer assisted sperm analysers is the immediate measurement of sperm concentration, total number of sperms in ejaculate and the automated calculation of number of insemination units which could be prepared from one ejaculate. Additionally some machines are equipped with UV excitation module, which gives the opportunity to analyse the percentage of live and dead spermatozoa after staining with vital fluorescent probes, such as Hoechst 33258. Nevertheless, CASA system needs standardization and validation before its use and image settings have been standardized 
(Davis \& Katz, 1992; Iguer-Ouada \& Verstegen, 2002; Rijsselaere et al., 2003; Verstegen et al., 2002). Also other factors as the type and depth of the used chamber, number of fields analysed, temperature during analysis and protocol of semen sample preparation affect results. Optimization and validation of the technical settings would allow to compare intraand inter-laboratory results, regardless of the instruments that have been used (Agarwal et al., 1992).

Computer assisted sperm analysis allows for a detailed estimation of subtle changes of sperm motion characteristics such as hyperactivation (HA) of spermatozoa associated with capacitation process. Hyperactivation is the process that mammalian spermatozoa exhibit, while they progress through the female oviduct. It is described as vigorous, nonprogressive, non-linear sperm motion linked with capacitation. During HA, the pattern of sperm track undergo dramatic changes, characterized by wide-amplitude marked lateral movements of the head and tail of the spermatozoon, with slow or non-progressive 'starpin' movement (Verstegen et al., 2002). Hyperactivated sperm movement, is assumed to be necessary, for mammalian sperms to penetrate into and pass through, the cumulus cell layer of an oocyte (Meyers et al., 1997; Suarez et al., 1983). To fertilize the oocyte, mammalian spermatozoa must be capacitated, the process that depends on the removal or alteration of substances absorbed on, or integrated in the sperm plasma membrane, resulting in changes in membrane permeability and intracellular ionic composition, with $\mathrm{Ca}^{2+}$ movements playing the most critical role (Fraser et al., 1995; Rota et al., 1999). ALH and velocity parameters such as path velocity VAP, progressive velocity VSL are increased in hyperactivated spermatozoa, whereas linearity LIN and straightness STR of movement are lowered. Such changes are characteristic for capacitation induced by specific media (Rota et al., 1999) and for spermatozoa that underwent preservation (cryocapacitation) and are pronounced, especially when media with addition of detergents are used (Niżański et al., 2009). Kawakami et al. (2001) observed that oviduct's epithelium possess the ability to bind hyperactivated spermatozoa, which results in the obvious prolongation of their flagellar movement. On the other hand, the life-span of the free moving non-bound hyperactivated spermatozoa within oviductal lumen, is relatively shorter. It was also found, that Ca influx into the cytoplasm is inhibited in the oviductepithelium-binding sperms (Dobrinsky et al., 1997). Active movement of the sperms and Ca influx into cytoplasm negatively affect the maintenance of viability and fertile life of sperm in the lumen of oviduct. Binding to the oviduct epithelium presumably prevents Ca influx, required for sperm capacitation. This phenomenon is available for prolonging viability and fertile life of canine sperms in the oviduct (Kawakami et al., 2001). Considering the obvious lack of such regulatory mechanism, in frozen-thawed semen it is believed, that in vitro post-thaw hyperactivation results in depletion in spermatozoa energy resources, accumulation of metabolites in the extender and cell death, if insemination dose is not deposited into the female's genital tract immediately after thawing.

Nevertheless, the computer assisted sperm analysis of cryopreserved semen should be treated with a dose of criticism. It should be emphasized, that CASA parameters describing kinematic features of frozen-thawed sperm cells may not reflect the real loss of quality of ejaculate after treatment. Absolute CASA parameters (VCL, VSL, VAP, ALH, BCF) should be used with caution, whereas relative CASA parameters (combinations of absolute 
features-LIN, STR) can not be used directly for estimation of semen quality. Selective death of the most immotile and weakened spermatozoa leads to the situation, where normal CASA parameters show the 'pseudoenhancement' of kinematics. Thus, the mean velocity and linearity parameters may be higher after freezing. This is caused by the fact, that the sub-population of the most resistant cells which survive freezing-thawing may possess higher mean quality parameters, than the larger population of motile sperm cells in fresh semen. In spite of the fact, that only half or one third of population of sperm cells may survive the cryopreservation, their mean velocity may be higher in comparison with velocity parameters of larger population of spermatozoa in fresh semen. Thus, some investigators (Katkov \& Lulat, 2000) observed increase in kinematic parameters (KP) of specimen after freezing-thawing, while at the same time substantial losses in post-thaw motility (percentage of motile cells) were observed. The possible explanation of this phenomenon is the selective elimination of the slowest sub-population within the specimens. This "CASA-paradox" is caused by substantial exclusion of slow-moving cells from the motile fraction measured after freezing-thawing.

Therefore, in order to obtain more reliable results of semen assessment after thawing, it was proposed to use Modified Kinematics Parameters (MKP) or Yield of Kinematic Parameters (YKP). MKP can be defined as KP that is average on an entire sample:

$$
\text { MKP }=\text { KP } \times \text { Motility } / 100 \%
$$

$\mathrm{YKP}$ is the product of KP and the number of motile cells for which this parameter is average:

$$
\text { YKP = Total Number of Motile Cells } \times \text { KP /100\% }
$$

Furthermore, morphology (Assisted Sperm Morphology Assessment-ASMA) of sperm cells can be objectively evaluated, on the basis of morphometric analysis of predefined specific measurements of particular elements in spermatozoa. Usually, on the slides, the head morphometric dimensions of length, width, width/length, area and perimeter of a minimum of 200 sperm are analyzed (Fig. 5). Additionally, parameters of head shape can be evaluated such as ellipticity, circularity, elongation, and regularity (Álvarez et al., 2008). Nevertheless, the accuracy of sperm morphology assessment depends on the careful preparation, fixation and staining of spermatozoa. The analysis of sperm morphology may be done using Diff-Quik stain recommended by World Health Organization (WHO, 2010) or SpermBlue, which has been developed for the evaluation of human and animal sperm morphology (Maree et al., 2010).

Rubio-Guillen et al. (2007) showed that by applying ASMA techniques and multivariate cluster analysis, it is possible to determine three subtle subpopulations of spermatozoa with different morphometric characteristics coexisting in bull ejaculates. The proportion of spermatozoa in each sperm subpopulation showed considerable differences among males and varied significantly throughout the cryopreservation procedure. The cryopreservation of spermatozoa has been found to affect chromatin structure and morphometry of the sperm head (Arruda et al., 2002; Esteso et al., 2003; Gravance et al., 1998; Hidalgo et al., 2006; Rijsselaere et al., 2004). Thus, it is presumed that the adverse effects of cryopreservation on sperm chromatin and head morphology, may be responsible for lowered fertility of spermatozoa, observed after cryopreservation. 


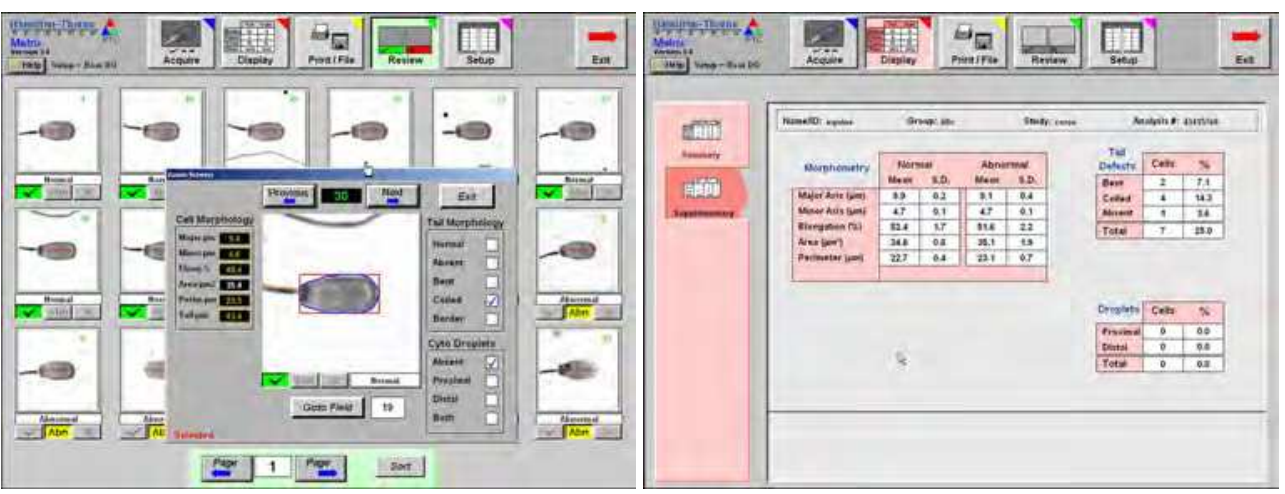

Fig. 5. System for Assisted Sperm Morphology Assessment.

\subsection{Flow cytometry and fluorescent probes}

During last decades many fluorescent probes have been used for the semen assessment. The fluorescence of these compounds may be estimated using fluorescent microscopy or flow cytometry. Flow cytometry enables the observation of physical characteristics such as cell size, shape, and also any component or function of the spermatozoon that can be detected by a fluorochrome or fluorescently labeled compound. The analysis is objective and accurate. The great number of spermatozoa $(>10000)$ can be analyzed in a small volume of samples in a short time. This is considerably more than the total of 200 cells generally observed by microscopic analysis. Thus, the analysis of events detected on dot plots gives the accurate and high reliable results (Peña et al., 2001). It is a sensitive method of detection of subtle differences among spermatozoal populations that may not be detected with other techniques.

\subsubsection{Sperm membrane integrity}

The integrity of sperm membranes is a necessary condition to maintain spermatozoal functions during storage in the female's reproductive tract and penetration of the oocyte (Holt, 2000). When semen is frozen, cells are exposed to a cold shock, ice crystals formation, and cellular dehydratation, which all cause irreversible damage (Amann, 1999; Parks \& Graham, 1992). Cellular membranes are one of the primary sites of injury during chilling, freezing and thawing. Damage is caused by alteration of membrane structure and lateral organization (Amann, 1999). The cryopreservation results in temperature-dependent and dehydratation-induced membrane phase changes, which are thought to result in lateral phase separation of membrane components and increased membrane permeability for solutes (Hammerstedt et al., 1990). The disruption of plasma membrane integrity caused by disarrangement of lipids within the membrane during cryopreservation may induce further cellular damage and consequently lead to a sperm death (Watson, 1995).

Membrane integrity of mammalian and avian spermatozoa may be assessed by using many fluorescent probe combinations including: carboxyfluorescein diacetate (CFDA) in combination with propidium iodide (PI), SYBR-14 with PI, carboxy-seminaphthorhodfluor (Carboxy-SNARF) with PI, calcein-AM with ethidium homodimer (EthD-1) and Hoechst 
33258 (Christensen et al., 2004; Donoghue et al., 1995; Hewitt \& England, 1998; Partyka et al., 2010; Peña et al., 1998; Rijsselaere et al, 2005; Sirivaidyapong et al., 2000). SYBR-14 and CFDA, usually used detectors of live cells, are membrane-permeant and non-fluorescent compounds, which are immediately deacylated and thus rapidly converted into high fluorescent compounds by intracellular esterases. These green fluorochromes are maintained intracellular by intact membranes (Peña et al., 1998; Silva \& Gadella, 2006). As plasma membrane deteriorate at cell death, cells lose their ability to resist the influx of red fluorescent PI. PI replaces or quenches green fluorochromes (Garner \& Johnson, 1995). Live, viable, intact spermatozoa show a green fluorescence (CFDA, SYBR-14, calcein-AM) while dead stain red (PI) (Fig. 6a). Carboxy-SNARF is pH indicator which stains live spermatozoa orange, while bisbenzimide stain Hoechst 33258 labels dead spermatozoa bright blue (Hewitt \& England, 1998). The last one requires flow cytometric analysis with a laser that operates in the ultraviolet light range and is less commonly used in andrology laboratory, however alternatively it may be applied within fluorescent microscope.

SYBR-14/PI fluorochromes have been found to be more sensitive in comparison with conventional method of live-dead cell assessment. The advantage of the use of fluorochromes is the possibility to assess the semen without the interference of fat particles and others material present in the extended semen (Rijsselaere et al., 2005). The detection of the third subpopulation i.e. moribund spermatozoa is the next advantage of this method. Additionally the simultaneous assessment of several functions of spermatozoa may be done in the same specimen by simultaneous staining of sperm cells with fluorescent lectins PNA or PSA for acrosome evaluation with PI for dead cell assessment.

\subsubsection{Acrosomal membrane integrity}

Acrosome is the acidic secretory organelle filled with hydrolytic enzymes. Assessment of the acrosomal status is a very important part of semen evaluation, in the view of the role of this structure in the maintenance of spermatozoal ability to penetrate the egg's zona pellucida (in mammals), or the egg envelope (in birds) and the ability to fuse with the egg plasma membrane. Cells must retain a normal acrosome to ensure that the acrosome reaction may occur at the suitable time to facilitate fertilization (Esteves et al., 2007). Also the determination of the acrosome status in cryopreserved sperm is of the fundamental importance as cryopreservation directly damages sperm membrane, which could be followed by a loss of the acrosomal matrix contents.

Acrosomal status may be assessed using lectins, such as peanut agglutinin from Arachis hypogaea (PNA) or Pisum Sativum agglutinin (PSA), conjugated with different fluorescent probes like fluorescein isothiocyanate (FITC), phycoerythryn (PE) or Alexa Fluor ${ }^{\circledR}$, (Graham et al., 1990; Kawakami et al., 2002; Nagy et al., 2004; Partyka et al., 2010; Peña et al., 2001; Rijsselaere et al., 2005). For human sperm concanavalin A lectins (ConA) is used as well (Holden et al., 1990). The PNA labelling is specific for the outer acrosomal membrane and it binds to $\beta$-galactose moieties. Whereas the PSA is labelling a-mannose and a-galactose moieties of the acrosomal matrix. The absence of the fluorescence on the living sperm is indicative for an intact acrosome, and fluorescence is indicative for acrosome disruption or acrosome reaction (Silva \& Gadella, 2006). Since PNA agglutinin displays less non-specific binding to other areas of the spermatozoa, it leads some researchers to favour this over PSA (Graham, 2001). Lectins may be also combined with Hoechst 33258, carboxy-SNARF/PI, 
ethidium homodimer allowing for simultaneous assessment of acrosomal status and membrane integrity (Fig. 6b) (Kawakami et al., 1993; Szász et al., 2000).

\subsubsection{Mitochondrial function}

The motility of spermatozoa subjected to cryopreservation is reduced by reason of some changes in the active transport and the permeability of the plasma membrane in the tail region (Blesbois et al., 2008; Watson, 1995). A reduction of spermatozoa motility may also be triggered by a change in the availability of energy or an injury of the axonemal elements. Moreover, it has been noted that the alterations in the ultrastructure of mitochondria occurring during cryopreservation are followed by a loss of the internal mitochondrial structure of frozen-thawed spermatozoa (Watson, 1995).

Rhodamine 123 (R123) is the potentiometric membrane dye which is used to selectively stain functional mitochondria. It fluoresces only when the proton gradient over the inner mitochondrial membrane (IMM) is built up and unstained sperm do not contain functional mitochondria (Garner et al., 1997; Gravance et al., 2001). Also the group of Mitotrackers: Mitotracker Deep Red, Red, Orange and Green selectively label the respirating mitochondria. Thus, these probes are suitable to discriminate sperm with deteriorated mitochondria from sperm in which oxidative respiration occurs (Gadella \& Harrison, 2002; Garner et al., 1997).

Some of mitotrackers such as 5,5',6,6'-tetrachloro-1,1',3,3'-tetraethylbenzimidazolylcarbocyanine iodide (JC-1) change their fluorescent properties due to changes in the potential of IMM. JC-1 is a lipophilic cationic fluorescent carbocyanine dye that is internalized by all functioning mitochondria, where it fluoresces green. However, as the concentration of JC-1 inside the mitochondria increases (highly functional mitochondria), the stain forms aggregates which fluoresce orange. Hereby, population of spermatozoa can be divided into high (orange staining), moderate (orange and green) and low (green) mitochondrial potential groups after IMM depolarisation (Fig. 6c) (Garner et al. 1999; Gravance et al., 2000).

\subsubsection{Capacitation status}

Before fertilizing of the oocyte, mammalian spermatozoa undergo the sequence of membrane alterations associated with accumulation of calcium ion and the increase of tyrosine phosphorylation resulting in sperm hyperactivation (Hewitt \& England, 1998; Petrunkina et al., 2003). At the contact with oocyte, capacitated spermatozoa presents the acrosome reaction which enables the zona pellucida penetration. However, in avian spermatozoa it is believed that a period of capacitation within the female's reproductive tract in order to fertilize ova is not required (Howarth, 1971). The hen oocyte is not surrounded by cumulus cells that would require a different way of sperm motility to pass them trough. It may therefore be suggested that there is no need for motility hyperactivation to prepare for the acrosome reaction in the chicken and that this special motility pattern has not been developed in birds (Lemoine et al., 2008).

The capacitation of the mammalian spermatozoa is assessed by using chlorotetracycline assay (CTC), lectins, measurements of CASA motility characteristics and assessment of thyrosine phosphorylation within plasma membrane (Guérin et al., 1999; Hewitt \& England, 
1998; Petrunkina et al., 2004; Rota et al., 1999). Fluorescent antibiotic CTC is used to assess the destabilization of sperm membrane. Neutral and uncomplexed CTC crosses over the cell membrane, enters intracellular compartments and binds to free calcium ions. During these events, CTC becomes negatively charged and after creating CTC-Ca+2 complexes becoms more fluorescent. Thus CTC can be used as a tool to distinguish capacitated and uncapacitated spermatozoa. Three classes of sperm cells may be assessed: uncapacitated and acrosome intact (F-pattern, an overall staining of the sperm head), capacitated and acrosome intact (B-pattern, a prominent staining of the apical area of the sperm head) and capacitated and acrosome reacted (AR-pattern, loss of staining of the sperm head) (Maxwell \& Johnson, 1997). CTC may be combined with Hoechst 33258, to simultaneous assessment of percentage of live cells and capacitation status (Hewitt \& England, 1998).

The exposure of spermatozoa to low temperatures shortens their capacitation time, changing the membrane lipid architecture, membrane permeability and the reducing efficiency of enzymes extruding calcium ions. These changes resemble capacitation, and are likely to reduce long-term sperm viability and alter their motility (Watson, 1995). Therefore, the researchers have introduced the term "cryocapacitation" to emphasize the fact that cryopreservation procedures induce capacitation-like changes in spermatozoa (Bailey et al., 2000; Cormier \& Bailey, 2003; Watson, 1995). These cooling-related capacitation-like changes in spermatozoa, may affect the fertility of cryopreserved semen, by rendering the cells less stable in the reproductive tract, after artificial insemination and therefore relatively short-lived. Such changes cannot easily be distinguished from true capacitation, but Green \& Watson (2001) were able to establish that the capacitation-like changes in pig spermatozoa differed from true capacitation in the pattern of tyrosine phosphorylation of proteins.

An increase in both, plasma membrane phospholipid scrambling and phospholipid disorder, during capacitation is associated with enhanced plasma membrane fluidity (Gadella \& Harrison, 2002). During freeze-thaw cycle, the sperm membranes undergo lipid phase transition that also leads to an increased disorder of phospholipid packing and membrane fluidity, which causes poor control of intracellular calcium concentration (Bailey \& Buhr, 1994; Holt, 2000). Therefore, an alternative stain for assessment of capacitation status of spermatozoa is the hydrophobic probe Merocyanine 540 (M540). This stain detects a decreased packing order of phospholipids in the outer leaflet of the plasma membrane lipid bilayer. Due to the fact that M540 earlier detects changes in the membrane fluidity than CTC, therefore, the hydrophobic probe is believed to be better for evaluating the early events of capacitation (Rathi et al., 2001).

\subsubsection{Lipid peroxidation}

A content of polyunsaturated fatty acids (PUFAs) in phospholipids of spermatozoa membranes makes them especially susceptible to lipid peroxidation (LPO) (Aitken et al., 1993). LPO is a chain reaction with the formation of lipid peroxides and ultimately the formation of cytotoxic aldehydes (Aitken, 1995). In spermatozoa, peroxidation of lipids has critical consequences. Oxidation reactions in biomembranes lead to amplification of reactive oxygen species (ROS), change in membrane fluidity, loss of compartmentalization and plasma-membrane integrity, disturbance of ion-gradients, impairment of lipid-protein interactions, modification of DNA and proteins (Halliwell \& Chiroco, 1993). 
Effect of oxidative stress is particularly important during the storage of sperm and its cryopreservation. The analysis of semen of mammalian and avian species, showed that the production of ROS and LPO occurrence is increased during freezing- thawing (Bilodeau et al., 2000; Chatterjee and Gagnon, 2001, Guthrie \& Welch, 2007; Neild et al., 2005; Partyka et al., 2011b). The main site of their formation are mitochondria (Brouwers \& Gadella, 2003) and sperm cell membranes (Agarwal et al., 2005), which are particularly vulnerable to damage from sudden temperature changes. Although, aerobic cells have substrates and enzymes to prevent or restrict the formation and propagation of ROS, but the antioxidant defence of spermatozoa are relatively weak and these germ cells are very susceptible to oxidative stress (Jones \& Mann, 1977).

As an alternative to the colorimetric detection of lipid peroxide formation, a fluorescent membrane probe 4,4-difluoro-5-(4-phenyl-1,3-butadienyl)-4-bora-3a,4a-diaza-s-indacene-3undecanoic acid ( $\mathrm{C}_{11}$-BODIPY581/591) has recently been successfully used in human, equine, bovine, porcine, feline and chicken's and goose's spermatozoa (Aitken et al., 2007; Almeida \& Ball, 2005; Brouwers \& Gadella, 2003; Brouwers et al., 2005; Neild et al., 2005; Partyka et al., 2011a,b; Thuwanut et al., 2009). This is an oxidation-sensitive fluorescent fatty acid analogue, that is easily incorporating into membranes and fluoresces red in the intact state,

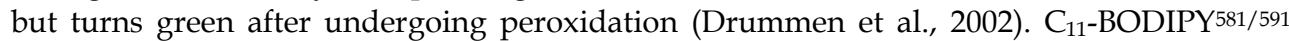
oxidation is virtually insensitive to environmental changes and the probe does not spontaneously leave the lipid bilayer after oxidation, moreover the extent of peroxidation is correlated with the formation of hydroxyl- and hydroperoxiphosphatidylcholine (Brouwers \& Gadella, 2003; Brouwers et al., 2005). The degree of probe peroxidation can be followed in separate sperm subpopulations using flow cytometry, or localized in individual sperm using fluorescence microscopy. Moreover, the use of combination $\mathrm{C}_{11}$-BODIPY581/591 with PI makes it possible to distinguish the presence of reactive oxygen and nitrogen species in the hydrophobic part of lipid bilayers of live sperm from dead cell membranes (Fig. 6d).

For monitoring the intracellular level of ROS, such as hydrogen peroxide $\left(\mathrm{H}_{2} \mathrm{O}_{2}\right)$ in the spermatozoa, the fluorescent dye 5-(and-6)-carboxy-20,70-dichlorodihydrofluorescein diacetate (carboxy-H2DCFDA) can be used. Viable spermatozoa are differentiated from dead cells by a counterstain - propidium iodide and the subpopulations of sperm with a high $\mathrm{H}_{2} \mathrm{O}_{2}$ level (strong fluorescence) and with low $\mathrm{H}_{2} \mathrm{O}_{2}$ level (weak fluorescence) can be distinguished.

\subsubsection{Apoptotic changes}

Apoptosis is a physiological mechanism required for any organism function. In contrast to necrosis, apoptosis is a process, where cells play an active role in their own death. Apoptosis comprising of a complex phenomenon that includes three stages: induction, execution and degradation. The most significant changes related to apoptosis are the externalization of the phosphatidylserine (PS), DNA fragmentation, caspase activation, loss of mitochondrial membrane potential, and increase in sperm membrane permeability (Bratton et al., 1997; Glander \& Schaller, 1999; Martin et al., 2004;). Several pathways are reported for mammalian cell apoptosis. These include the intrinsic, extrinsic, and apoptosis-inducing factors. During the early phases of disturbed membrane function, asymmetry of the membrane phospholipids occurs, before the integrity of the plasma membrane is 
progressively damaged (Martin et al., 1995). When the cell membrane is disturbed, the phospholipid PS is translocated from the inner to the outer leaflet of the plasma membrane (Desagher \& Martinou, 2000).

It is widely known that the cryopreservation usually causes sublethal cryodamage to spermatozoa, decreasing post-thaw cell viability. The freezing-thawing of human (Glander \& Schaller, 1999), bull (Martin et al., 2004), and boar (Pena et al., 2003), stallion (Ortega Ferrusola et al., 2008), and dog (Kim et al., 2010) spermatozoa induces membrane PS translocation, what demonstrates that cryopreservation leads to apoptosis. Therefore, detecting early phases of membrane dysfunction, or initial phases of apoptosis of viable spermatozoa, would be important when evaluating stressed spermatozoa, such as those subjected to freezing and thawing, and would be useful for controlling freezing procedures in semen.

Annexin V is calcium-dependent phosphatidylserine (PS) binding protein conjugated with fluorochrome - FITC or Alexa Fluor ${ }^{\circledR}$. The properties of Annexin V allow for detection of externally exposed PS. In ejaculated spermatozoa PS is confined to the cytoplasmatic side of the plasma membrane (Gadella et al., 1999). Different categories of apoptotic, necrotic and viable cells can then be sorted out using AnnexinV with PI, through flow cytometer (Fig. 6e), or visually evaluated using fluorescent microscope.

After induction of apoptosis, mitochondrial pores are being opened, leading to a decrease in mitochondrial membrane potential. Therefore, described above JC-1 dye is used for monitoring of apoptotic changes in spermatozoa, too (Ortega Ferrusola et al., 2009). Mentioned above, the opening of mitochondrial pores causes the release of proapoptotic factors into the cytoplasm, where they are activated. These factors - caspases, are central components in the apoptosis signaling cascade. The detection of activated caspases in living spermatozoa can be performed using fluorescence labeled inhibitors of caspases (FLICA ${ }^{\mathrm{TM}}$ ). It allows investigating caspase activation in semen samples with regard to a single cell. The FLICA $^{\mathrm{TM}}$ reagent is comprised of 3 segments-it includes a green (FAM 5 carboxyfluorescein) fluorescent label; an amino acid peptide inhibitor sequence targeted by the active caspase; and a fluoromethylketone group (FMK), which acts as a leaving group and forms a covalent bond with the active enzyme. Fluorescence labeled inhibitors of caspases are cell permeable and noncytotoxic (cited by Grunewald et al., 2009). Martin et al. (2004) showed that cryopreservation of bovine spermatozoa induced the significant increase in the proportion of cells with active caspases, which were mainly detected in the intermediate piece of spermatozoa.

\subsubsection{DNA status of spermatozoa}

DNA integrity has been considered as an important parameter in the determination of spermatozoa ability to withstand the cryopreservation process. It is suggested that chromatin structure should be studied as an independent complementary parameter for the better assessment of the sperm quality (Evenson et al., 2002). The spermatozoal chromatin is much more compact when compared to somatic and spermatogenic cell types (e.g., spermatognia, spermatocytes and spermatids). It appears that during freezing-thawing procedure the integrity of the nuclear DNA, which is related to fertility, could be negatively 
affected. Although, spermatozoa with DNA damage may be able to fertilize an oocyte, that could potentially disturb (epi)genetic regulation of the early embryo and block its further development (Lewis \& Aitken, 2005).

DNA damage can be evaluated at different levels. One of the usually used methods, developed for detecting changes in the chromatin structure of DNA integrity, is the sperm chromatin structure assay (SCSA) (Chohan et al., 2006). The SCSA is a flow cytometric method for identification of changes in the DNA status. It is based on the assumption that a structurally abnormal sperm chromatin shows a higher susceptibility to acid denaturation (Evenson et al., 2002). The SCSA method utilizes the metachromatic properties of acridine orange $(\mathrm{AO})$. This stain fluoresces in the green band when intercalates into the intact double-stranded DNA helix, and in the red band when associated with single strand denaturated DNA and RNA. After denaturation of chromatin by decreased $\mathrm{pH}$, the spermatozoa with structurally abnormal chromatin fluorescence is detected in the red band (Fig. 6f) (Bochenek et al., 2001). The fertility data have been shown to correlate with the results obtained from the SCSA of human (Evenson et al., 1980), bull (Ballachey et al., 1988; Karabinus et al., 1990), stallion (Love \& Kenney, 1998) and boar semen (Evenson et al., 1994). SCSA was also used for dog semen assessment (Garcia-Macias et al, 2006) and for evaluation of freezing-thawing effect on chicken and goose DNA status (Partyka et al. 2010; Partyka et al., 2011b).

Another method to detect DNA defragmentation is TUNEL assay, which allows to incorporate of fluorescent nucleotide analogs by a terminal nucleotide transferase into single stranded DNA areas at the 3-OH termini (Chohan et al., 2006). Ramos \& Wetzels (2001) using this method have shown that DNA damage is limited in functional human spermatozoa resulting from a swim-up procedure.

The alternative method for detecting the DNA damage at the level of individual cells is the single-cell DNA gel electrophoresis assay (COMET). Although this method does not use such equipment as flow cytometry, application of fluorescent DNA specific stain is required. In COMET assay spermatozoa are spread on a surface covered with an agarose gel, and treated with a solution that lyses the cell components leaving the DNA immobilized in the agarose. They are then subjected to a DNA denaturation process, followed by electrophoresis, causing DNA fragments to migrate away from the main bulk of nuclear DNA. After staining with propidium iodide or ethidium bromide, cells with DNA strand breaks, display a comet-like shape, with the undamaged DNA located in the head of the comet and the fragmented DNA dispersed through the tail. Image analyses provide information on the extent of strand breaks in the DNA molecule. Several studies, conducted with different techniques, including comet assay, showed a negative relationship between the fertilization potential of spermatozoa and alterations at the level of genetic material. In particular in humans, infertility has been associated with higher levels of DNA damage in sperm compared to fertile subjects (Irvine et al., 2000). Fraser \& Strzeżek (2007) have shown that the freezing-thawing process provoked sperm chromatin destabilization rendering the boar spermatozoa more vulnerable to DNA fragmentation. COMET assay has also been recently used for the evaluation of cryopreserved avian semen (Madeddu et al., 2010; Gliozzi et al., 2011). 


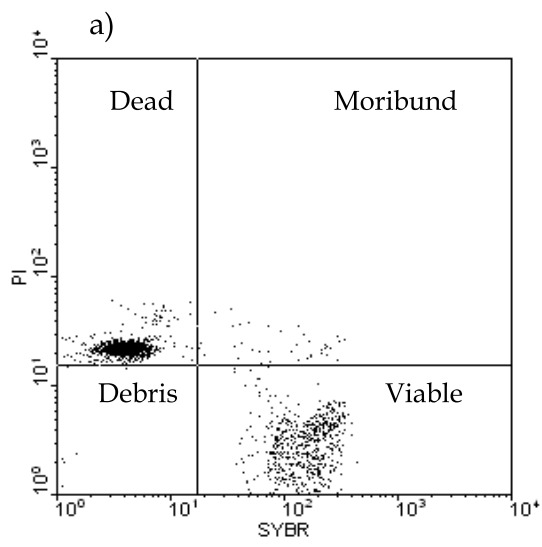

b)

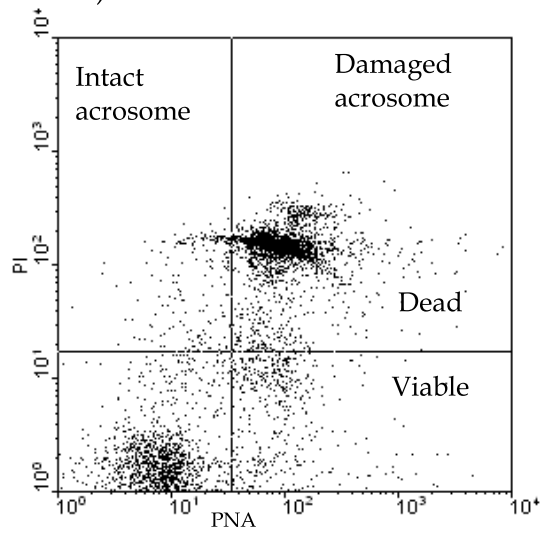

c)
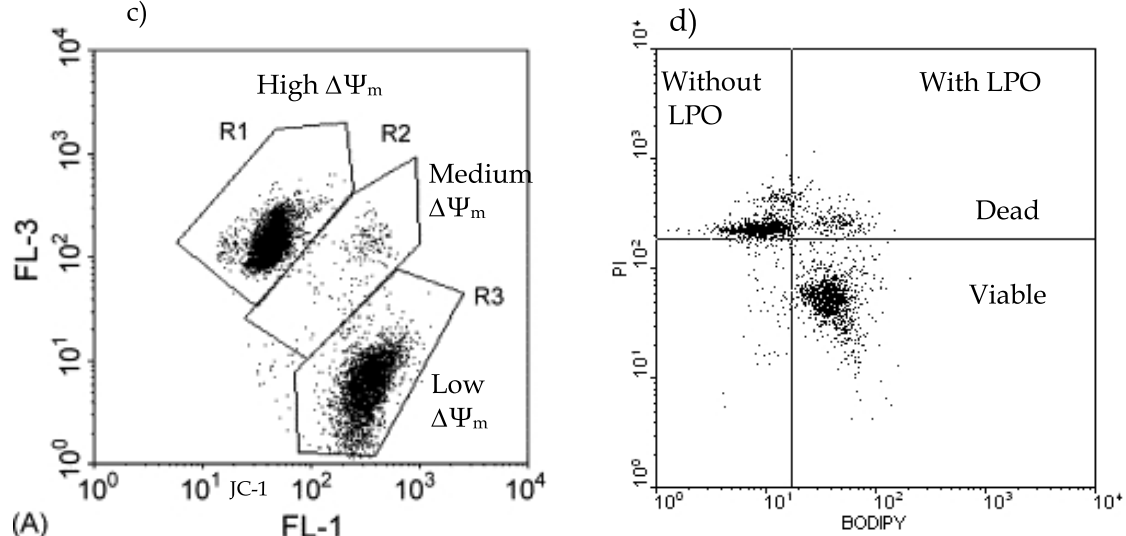

e)

f)
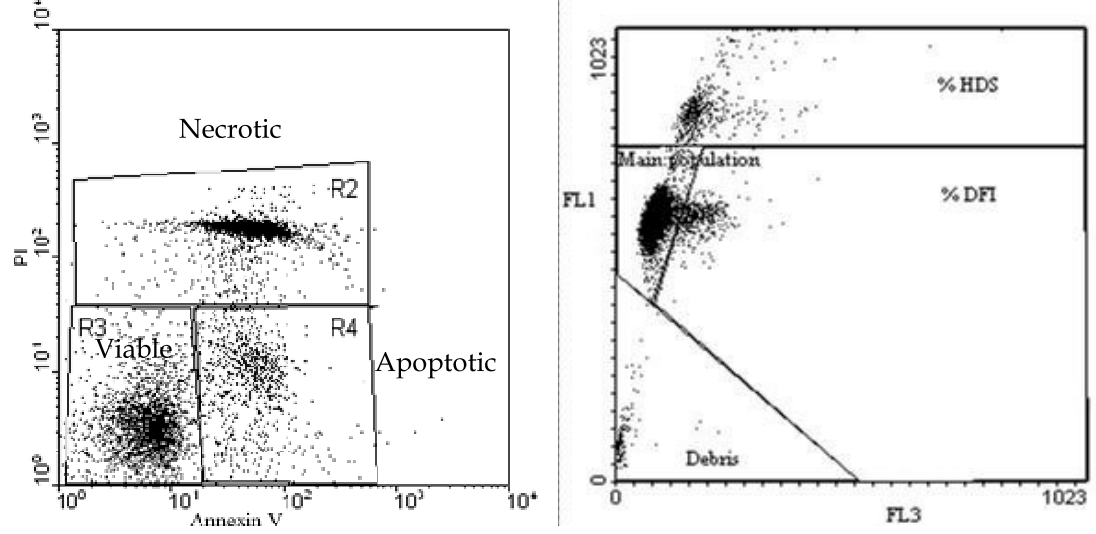

Fig. 6. Examples of flow cytometry analyses of frozen-thawed spermatozoa: a) Dot plot of SYBR-14/PI stain. Four subpopulations can be distinguished: dead sperm (red stained), 
moribund sperm (red/green fluorescence), viable sperm (green stained), unstained debris are discarded; b) Dot plot of PNA-AlexaFluor/PI stain. Spermatozoa can be identified as: acrosome - intact/damaged, together with selection - viable/dead, according to their green and red fluorescence; c) Dot plot of JC-1 staining for mitochondrial status analysis. The intensity of orange fluorescence depends on mitochondrial membrane potential $\left(\Delta \Psi_{\mathrm{m}}\right)$ allowing for differentiation between high, medium and low $\Delta \Psi_{m} ;$ d) Dot plot of $C_{11}$ BODIPY581/591/PI for assessment of lipid peroxidation (LPO). Spermatozoa can be divided into four subpopulations: dead without LPO, dead with LPO, live without LPO and live with LPO; e) Dot plot of Annexin V/PI stain. Spermatozoa can be identified as: viable, necrotic and apoptotic; f) Dot plot of SCSA using acridine orange. The distribution of spermatozoa is based on green (FL1) and red (FL3) fluorescence. Main population includes sperm without DNA fragmentation, \%DFI represents the percentage of sperm with detectable DNA fragmentation and \% HDS determines the percentage of immature cells.

\subsection{In vitro gamete interaction tests}

During fertilization, a sperm initially binds to the oocyte zona pellucida (ZP), undergoes the acrosome reaction (AR), penetrates the $\mathrm{ZP}$, and fuses with the oolemma to form a zygote. Sperm-ZP interactions are carbohydrate-mediated events in various species, including humans (Benoff, 1997). The ZP of mammalian oocytes is a critical site for sperm-oocyte interaction. The ability of sperm to bind to the ZP indicates many functions of spermatozoa, such as viability, motility, morphology, acrosomal status and the ability to penetrate the oocyte (Liu \& Baker, 1994), and for that reason this ability is of a diagnostic relevance.

\subsubsection{Zona pellucida binding assay}

The assessment of the ability of sperm cells to bind the homologous zona pellucida (ZP) is the useful test for prediction of spermatozoal fertilizing ability (Hermansson et al., 2006). It is assumed that it is reliable test to detect sperm damage at a molecular level, which is not visible by microscopic analysis, because binding is receptor-ligand mediated reaction. The test may be done in two ways: by using intact homologous oocytes (ZP-binding assay, ZBA) and by using bisected hemizonae (hemizona binding assay, HZA) (Kawakami et al., 1998; Rijsselaere et al., 2005). In ZBA spermatozoa are coincubated with oocytes obtained from sliced ovaries. The number of spermatozoa that bound to ZP is counted with contrast-phase microscopy. The disadvantage of ZBA is the fact that the attachment of sperm cells to zona depends on the oocyte. This feature was partly overcome in HZA. Bisected by micromanipulation two parts of ZP are coincubated with spermatozoa. As a result the direct comparison of sperm cells from two origins may be done (Ivanova et al., 1999; MayencoAguirre \& Pérez Cortés, 1998).

A sublethal damage that occurres during cryopreservation leads to loss of sperm surface proteins, segregation of membrane proteins, inactivation of membrane-bound enzymes and decreased lateral protein diffusion within the membrane (Watson, 1995). Kadirvel et al. (2011) observed significant reduction of the zona binding ability of cryocapacitated buffalo bulls spermatozoa, and further reduction of binding ability of frozen-thawed spermatozoa, after incubation, in either capacitating, or non capacitating medium. Similar results have been obtained in bulls (Fazeli et al., 1997) and humans (Amann et al., 1999) spermatozoa, with significantly reduced binding ability to the zona pellucida after freezing and thawing. 
The reduced binding ability of the frozen-thawed spermatozoa might be due to the higher proportion of acrosome reacted and damaged spermatozoa, after cryopreservation and thawing. Moreover, impaired receptor-ligand interaction in frozen-thawed spermatozoa could be caused by cryoelution of an "essential ligand" from the sperm surface that has been described in human (Amann et al., 1999).

\subsubsection{Oocyte penetration assay}

Oocyte penetration assays (OPT) involve multiple sperm penetrations of each oocyte and permit the observation of pronuclear development (Yanagimachi et al., 1976). The application of the zona-free hamster oocyte assay has been used to assess the fertility of men (Freeman et al., 2001; ) and domestic animals (Cormier et al., 1997; De los Reyes et al., 2009; Hewitt \& England, 1997; Maxwell et al., 1996;). The OPT is a less time-consuming technique than in vitro fertilization (IVF) test, because oocytes can be immatured, and after evaluation are not further subjected to development. In this assay spermatozoa presented in the pervitelline space and ooplasm of the oocytes are observed under fluorescent microscopy using Hoechst 33258, PI or light microscopy (aceto-orcein) (Hay et al., 1997; Hewitt \& England, 1997).

All changes in cryopreserved spermatozoa described in the above sections may affect the final percentage of fertilized oocytes, and also the time course of sperm penetration through the oocyte envelop, as reported previously in frozen-thawed ram and bovine sperm (Cormier et al., 1997; Maxwell et al., 1996). Nevertheless, the previous study has indicated that the major ability of cryopreserved sperm to penetrate oocytes occurs at the 1st hour of co-culture (Cormier et al., 1997; De los Reyes et al., 2009). This finding indicates that these sperm can undergo the events associated with fertilization earlier or faster than fresh sperm in relation with cryocapacitation appearance.

Because the efficiency of oocyte penetration is a result of sperm-oocyte interaction, variation in oocyte properties are likely to produce large diversity in this assay results. However, this can be reduced with the use of a large number of oocytes (Lucas et al., 2003). However, in dogs in vitro maturation (IVM) of oocytes and IVF is difficult to achieve. Nevertheless capacitated dog spermatozoa are able to penetrate immature oocytes, inducing chromatin decondensation and resumption of meiosis (Luvoni et al., 2005; Hay et al., 1994; Sain-Dizier et al., 2001). Thus, in dogs both, immature or mature oocytes, may be use for this test.

\section{Conclusions}

For many years, scientists have made every endeavour to develop laboratory assays that precisely estimate the fertilizing capacity of semen. Laboratory semen appraisals can be classified in several ways. Nevertheless, an important factor for a laboratory analysis to be useful, it must be objective, repeatable, accurate and as far as possible, rapid. Among others, there can be distinguished one major division into conventional methods and advanced techniques of sperm assessment. It is little questionable, whether the subjective assessment of parameters related to the functional and morphological characteristics of spermatozoa, would increase the predictability of the fertilizing potential of cryopreserved semen. However, conventional methods for sperm evaluation in connection with the more objective computer-assisted sperm analyzers, flow cytometry and in vitro fertilization tests, have 
enabled researchers to gain accurate information about the morpho-functional status of spermatozoa and mechanisms of sperm cryoinjury.

\section{Acknowledgments}

This work was supported by the Polish National Science Centre, grant no N N311 530040.

\section{References}

Agarwal, A.; Ozturk E. \& Loughlin, K.R. (1992). Comparison of semen analysis between the two Hamilton-Thorn semen analysers. Andrologia 24, 327-329.

Agarwal, A.; Prabakaran, S.A. \& Said T.M. (2005). Prevention of oxidative stress injury to sperm. J Androl 26, 654-60.

Aitken, R.J. (1995). Free radicals, lipid peroxidation and sperm function. Reprod Fertil Dev 7, 659-668.

Aitken, R.J.; Harikss, D. \& Buckingham, DW. (1993). Analysis of lipid peroxidation mechanisms in human spermatozoa. Mol Reprod Dev 35, 302-315.

Aitken, R.J.; Wingate, J.K.; De Iuliis, G.N. \& McLaughlin, E.A. (2007). Analysis of lipid peroxidation in human spermatozoa using BODIPY C11. Mol Hum Reprod 13, $203-$ 211.

Almeida, J. \& Ball, B.A. (2005). Effect of a-tocopherol and tocopherol succinate on lipid peroxidation in equine spermatozoa. Anim Reprod Sci 87, 321-337.

Álvarez, M.; García-Macías, V.; Martínez-Pastor, F.; Martínez, F.; Borragán, S.; Mata, M.; Garde, J.; Anel, L. \& De Paz, P. (2008). Effects of cryopreservation on head morphometry and its relation with chromatin status in brown bear (Ursus arctos) spermatozoa. Theriogenology 70, 1498-1506.

Amann, R.P. (1999). Cryopreservation of sperm. In: Encyclopedia of Reproduction, vol. 1. Academic Press, Burlington, MA, USA, 773-783.

Amann, R.P.; Shabanowitz, R.B.; Huszar, G. \& Broder, S.J. (1999). In vitro sperm-binding assay to distinguish differences in populations of human sperm or damage to sperm resulting from cryopreservation. J Androl 20, 648-654.

Arruda, R.P.; Ball, B.A.; Gravance, C.G.; Garcia, A.R. \& Liu IKM. (2002). Effects of extender and cryoprotectants on stallion sperm head morphometry. Theriogenology 58, 253-6.

Bailey, J.L. \& Buhr, M.M. (1994). Cryopreservation alters the Ca2+ flux of bovine spermatozoa. Can J Anim Sci 74, 45-52.

Bailey, J.L., Bilodeau J.F. \& Cormier, N. (2000). Semen cryopreservation in domestic animals: a damaging and capacitating phenomenon. J Androl 21, 1-7.

Ballachey, B.E.; Evenson, D.P. \& Saacke, R.G. (1988). The sperm chromatin structure assay. Relationship with alternate tests of semen quality and heterospermic performance of bulls. J Androl 9, 109-115.

Benoff, S. (1997). Carbohydrates and fertilization: an overview. Mol Hum Reprod 3, 599-637.

Bilodeau, J-F., Chatterjee, S.; Sirard, M-A. \& Gagnon, C. (2000). Levels of antioxidant defences are decreased in bovine spermatozoa after a cycle of freezing and thawing. Mol Reprod Dev 55, 282-288.

Blesbois, E.; Grasseau, I.; Seigneurin, F.; Mignon-Grasteau, S.; Saint Jalme, M. \& MialonRichard, M.M. (2008). Predictors of success of semen cryopreservation in chickens. Theriogenology 69, 252-261. 
Blom, E. (1950). Interpretation of spermatic cytology in bulls. Fertil Steril 1, 223-38.

Blom, E. (1968). A new sperm defect-"Pseudodroplets" - in the middle piece of the bull sperm. Nord Vet Med 20, 279-283.

Blom, E. (1983). Pathological conditions in the genital organs and in the semen as ground for rejection of breeding bulls for import or export to and from Denmark, 1958-1982. Nord Vet Med 35, 105-130.

Bochenek, M.; Smorąg, Z. \& Pilch, J. (2001). Sperm chromatin structure assay of bulls qualified for artificial insemination. Theriogenology 56, 557-567.

Bratton, D.L.; Fadok, V.A.; Richter, D.A.; Kailey, J.M.; Guthrie, L.A. \& Henson, P.M. (1997). Appearance of phosphatidylserine on apoptotic cells requires calcium-mediated nonspecific flip-flop and is enhanced by loss of the aminophospholipid translocase. J Biol Chem 272, 26159-26165.

Brito, L.F.; Barth, A.D.; Bilodeau-Goeseels, S.; Panich, P.L. \& Kastelic, J.P. (2003). Comparison of methods to evaluate the plasmalemma of bovine sperm and their relationship with in vitro fertilization rate. Theriogenology 60, 1539-1551.

Brito, L.F.; Greene, L.M.; Kelleman, A.; Knobbe, M. \& Turner, R. (2011). Effect of method and clinician on stallion sperm morphology evaluation. Theriogenology 76, 745-750.

Brouwers, J.F.H.M. \& Gadella, B.M. (2003). In situ detection and localization of lipid peroxidation in individual bovine sperm cells. Free Radical Biol Med 35, 1382-1391.

Brouwers, J.F.H.M.; Silva, P.F.N. \& Gadella, B.M. (2005). New assay for detection and localization of endogenous lipid peroxidation products in living boar sperm after BTS dilution or after freeze-thawing. Theriogenology 63, 458-469.

Chatterjee, S. \& Gagnon, C. (2001). Reproduction of reactive oxygen species by spermatozoa undergoing cooling, freezing, and thawing. Mol Reprod Dev 59, 451-458.

Chohan, K.R.; Griffin, J.T.; Lafromboise, M. \& De Jonge, C.J. (2006). Comparison of chromatin assays for DNA fragmentation evaluation in human sperm. J Androl 27, 53-59.

Christensen, P.; Stenvang, J.P. \& Godfrey, W.L. (2004). A flow cytometric method for rapid determination of sperm concentration and viability in mammalian and avian semen. J Androl 25, 255-264.

Coetzee, K.; Kruger, T.F.; Lombard, C.J.; Shaughnessy, D.; Oehninge,r S.; Ozgür, K.; Pomeroy, K.O. \& Muller C.H. (1999). Assessment of interlaboratory and intralaboratory sperm morphology readings with the use of a Hamilton Thorne Research integrated visual optical system semen analyzer. Fertil Steril 71, 80-84.

Colenbrander, B.; Gadella, B. \& Stout, T. (2003). The Predictive Value of Semen Analysis in the Evaluation of Stallion Fertility. Reprod Domest Anim 38, 305-311.

Cormier, N. \& Bailey J.L. (2003). A differential mechanism is involved during heparin-and cryopreservation-induced capacitation. Biol Reprod 69, 177-185.

Cormier, N.; Sirard, M.A. \& Bailey, J. (1997). Premature capacitation of bovine spermatozoa is initiated by cryopreservation. J Androl 18, 457-461.

Correa, J.R. \& Zavos, P.M. (1994). The hypoosmotic swelling test: its employment as an assay to evaluate the functional integrity of the frozen-thawed bovine sperm membrane. Theriogenology 42, 351-360.

Davis, R.O. \& Katz D.F. (1992). Standardization and comparability of CASA instruments. J Androl 13, 81-86. 
De los Reyes, M.; Palomino J.; de Lange, J.; Anguita, C. \& Barros, C. (2009). In vitro sperm penetration through the zona pellucida of immature and in vitro matured oocytes using fresh, chilled and frozen canine semen. Anim Reprod Sci 110, 37-45.

Desagher, S. \& Martinou, J.C. (2000). Mitochondria as the central control point of apoptosis. Trends Cell Biol 10, 369-77.

Didion, B.A.; Dobrinsky, J.R.; Giles, J.R. \& Graves, C.N. (1989). Staining procedure to detect viability and the true acrosome reaction in spermatozoa of various species. Gamete Res 22, 51-57.

Dobrinski, I..; Smith, T.T.; Suarez, S.S. \& Ball, A.B. (1997). Membrane contact with oviductal epithelium modulates the intracellular calcium concentration of equine spermatozoa in vitro. Biol. Reprod 56, 861-869.

Donoghue, A.M.; Garner, D.L.; Donoghue, D.J. \& Johnson, L.A. (1995). Viability assessment of turkey sperm using fluorescent staining and flow cytometry. Poult Sci 74, 11911200.

Drummen, G.P.; Van Liebergen, L.C.M.; Op Den Kamp, J.A.F. \& Post, J.A. (2002). C11BODIPY581/591, an oxidation-sensitive fluorescent lipid peroxidation probe: (micro)spectroscopic characterization and validation of methodology. Free Radical Biol Med 33, 473-490.

Esteso, M.C.; Fernandez-Santos, M.R.; Soler, A.J. \& Garde, J.J. (2003). Head dimensions of cryopreserved red deer spermatozoa are affected by thawing procedure. Cryo Letters 24, 261-268.

Esteves, S.C.; Sharma, R.K.; Thomas, A.J. \& Agarwal, T.A. (2007). Evaluation of acrosomal status and sperm viability in fresh and cryopreserved specimens by the use of fluorescent Peanut agglutinin lectin in conjunction with hypo-osmotic swelling test. Int Braz J Urol 33, 364-376.

Evenson, D.P.; Darzynkiewicz, Z. \& Melamed, M.R. (1980). Relation of mammalian sperm chromatin heterogeneity to fertility. Science 210, 1131-1133.

Evenson, D.P.; Larson, K.L. \& Jost, L.K. (2002). Sperm chromatin structure assay: its clinical use for detecting sperm DNA fragmentation in male infertility and comparisons with other techniques. J Androl 23, 25-43.

Evenson, D.P.; Thompson, L. \& Jost, L. (1994). Flow cytometric evaluation of boar semen by the sperm chromatin structure assay as related to cryopreservation and fertility. Theriogenology 41, 637-651.

Fazeli, A.R.; Zhang, B.R.; Steenweg, W.; Larsson, B.; Bevers, M.M.; van den Broek, J.; Rodriguez-Martinez, H. \& Colenbrander, B. (1997). Relationship between spermzona pellucida binding assay and the 56-day nonreturn rate of cattle inseminated with frozen-thawed semen. Theriogenology 48, 853-863.

Fraser, L.R.; Abeydeera, L.R. \& Niwa, K. (1995). $\mathrm{Ca}^{+2}$-regulating mechanisms that modulate bull sperm capacitation and acrosome exocytosis as determined by chlortetracycline analysis. Mol Reprod Dev 40, 233-241.

Fraser, L. \& Strzeżek J. (2007). Is there a relationship between the chromatin status and DNA fragmentation of boar spermatozoa following freezing-thawing? Theriogenology 68, 248-257.

Freeman, M.R.; Archibong, A.E.; James, J.; Mrotek, C.M.; Whitworth, G.A. \& Weitzman, G.A. (2001). Hill. Male partner screening before in vitro fertilization: preselecting 
patients who require intracytoplasmic sperm injection with the sperm penetration. Fertil Steril 76, 1113-1118.

Freneau, G.E. ; Chenoweth, P.J. ; Ellis, R. \& Rupp, G. (2010). Sperm morphology of beef bulls evaluated by two different methods. Anim Reprod Sci 118, 176-181.

Gadella, B.M.; Miller, N.G.; Colenbrander, B.; van Golde, L.M. \& Harrison, R.A. (1999). Flow cytometric detection of transbilayer movement of fluorescent phospholipid analogues across the boar sperm plasma membrane: elimination of labeling artifacts. Mol Reprod Dev 53, 108-125.

Gadella, B.M. \& Harrison, R.A. (2002). Capacitation induces cyclic adenosine 3',5'monophosphate-dependent, but apoptosis-unrelated, exposure of aminophospholipids at the apical head plasma membrane of boar sperm cells. Biol Reprod 67, 340-350.

Garcia-Macias, V.; Martinez-Pastor, F.; Alvarez, M.; Garde, J.J.; Anel, E.; Anel, L. \& de Paz, P. (2006). Assessment of chromatin status (SCSA $\left.{ }^{\circledR}\right)$ in epididymal and ejaculated sperm in Iberian red deer, ram and domestic dog. Theriogenology 66, 1921-1930.

Garner, D.L. \& Thomas, C.A. (1999). Organelle-specific probe JC-1 identifies membrane potential differences in the mitochondrial function of bovine sperm. Mol Reprod Dev $53,222-229$.

Garner, D.L. \& Johnson L.A. (1995). Viability assessment of mammalian sperm using SYBR14 and Propidium Iodide. Biol Reprod 53, 276-284.

Garner, D.L.; Thomas, C.A.; Joerg, H.W.; DeJarnette, J.M. \& Marshall, C.E. (1997). Fluorometric assessments of mitochondrial function and viability in cryopreserved bovine spermatozoa. Biol Reprod 57, 1401-1406.

Glander, H.J. \& Schaller, J. (1999). Binding of annexin V to plasma membranes of human spermatozoa: a rapid assay for detection of membrane changes after cryostorage. Mol Hum Reprod 5, 109-115.

Gliozzi, T.M.; Zaniboni, L. \& Cerolini, S. (2011). DNA fragmentation in chicken spermatozoa during cryopreservation. Theriogenology 75, 1613-1622.

Graham, J.K. (2001). Assessment of sperm quality: a flow cytometric approach. Anim Reprod Sci 68, 239-247.

Graham, J.K.; Kunze, E. \& Hammerstedt, R.H. (1990). Analysis of sperm cell viability, acrosomal integritiy, and mitochondrial function using flow cytometry. Biol Reprod $43,55-64$.

Gravance, C.G.; Garner, D.L.; Miller, M.G. \& Berger, T. (2001). Fluorescent probes and flow cytometry to assess rat sperm integrity and mitochondrial function. Reprod Toxicol $15,5-10$.

Gravance, C.G.; Garner, D.L.; Baumber, J. \& Ball, BA. (2000). Assessment of equine sperm mitochondrial function using JC-1. Theriogenology 53, 1691-1703.

Gravance, C.G.; Vishwanath, R.; Pitt, C.; Garner, D.L. \& Casey, P.J. (1998). Effects of cryopreservation on bull sperm head morphometry. J Androl 19, 704-709.

Green, C.E. \& Watson, P.F. (2001). Comparison of the capacitation-like state of cooled boar spermatozoa with true capacitation. Reproduction 122, 889-898.

Grunewald, S.; Sharma, R.; Paasch, U.; Glander, H.J. \& Agarwal, A. (2009). Impact of Caspase Activation in Human Spermatozoa. Micros Res Techniq 72, 878-888. 
Guérin, P. ; Ferrer, M. ; Fontbonne, A. ; Bénigni, L. ; Jacquet, M. \& Ménézo, Y. (1999). In vitro capacitation of dog spermatozoa as assessed by chlortetracycline staining. Theriogenology 52, 617-628.

Guthrie, H.D. \& Welch, G.R. (2007). Use of fluorescence-activated flow cytometry to determine membrane lipid peroxidation during hypothermic liquid storage and freeze-thawing of viable boar sperm loaded with 4,4-difluoro-5-(4-phenyl-1,3butadienyl)-4-bora-3a,4a-diaza-s-indacene-3-undecanoic acid. J Anim Sci 85, 14021411.

Halliwell, B. \& Chiroco S. (1993). Lipid peroxidation: its mechanism, measurement and significance. Am J Clin Nutr 57, 715-725.

Hammerstedt, R.H.; Graham, J.K. \& Nolan, J.P. (1990). Cryopreservation of mammalian sperm: what we ask them to survive. J Androl 11, 73-88.

Hay, M.A.; King, W.A.; Gartley, C.J. \& Goodrowe, K.L. (1994). Influence of spermatozoa on in vitro nuclear maturation of canine ova. Biol Reprod 50, 362.

Hay, M.A.; King, W.A.; Gartley, C.J.; Leibo, S.P. \& Goodrowe, K.L. (1997). Effects of cooling, freezing and glycerol on penetration of oocytes by spermatozoa in dogs. J Reprod Fertil (Suppl. 51), 99-108.

Hermansson, U.; Ponglowhapan, S.; Linde-Forsberg, C. \& Ström-Holst, B. (2006). A short sperm-oocyte incubation time ZBA in the dog. Theriogenology 66, 717-725.

Hewitt, D.A. \& England, G.C. (1998). An investigation of capacitation and the acrosome reaction in dog spermatozoa using a dual fluorescent staining technique. Anim Reprod Sci 51, 321-332.

Hewitt, D.A. \& England, G.C.W. (1997). The canine oocyte penetration assay; its use as an indicator of dog spermatozoa performance in vitro. Anim Reprod Sci 50, 123-139.

Hidalgo, M.; Rodriguez, I. \& Dorado, J.M. (2006). The effect of cryopreservation on sperm head morphometry in Florida male goat related to sperm freezability. Anim Reprod Sci 100, 61-72.

Holden, C.A.; Hyne, R.V.; Sathananthan, A.H. \& Trounson, A.O. (1990). Assessment of the human sperm acrosome reaction using concanavalin A lectin. Mol Reprod Dev 25, 247-257.

Holt, W.V. (2000). Fundamental aspects of sperm cryobiology: the importance of species and individual differences. Theriogenology 53, 47-58.

Howarth, B.Jr. (1970). An examination for sperm capacitation in the fowl. Biol Reprod 3338 341.

Iguer-Ouada, M. \& Verstegen J. P. (2001). Validation of the Sperm Quality Analyzer (SQA) for dog sperm analysis. Theriogenology 55, 1143-1158.

Irvine, D.S.; Twigg, J.P.; Gordon, E.L.; Fulton, N.; Milne, P.A. \& Aitken, R.J. (2000). DNA integrity in human spermatozoa: relationships with semen quality. J Androl 21, 3344.

Ivanova, M.; Mollova, M.; Ivanova-Kicheva, M.G.; Petrov, M.; Djarkova, T. \& Somlev, B. (1999). Effect of cryopreservation of zona-binding capacity of canine spermatozoa in vitro. Theriogenology 52, 163-170.

Jeyendran, R.S.; van der Venn, H.H. \& Zaneveld, L.J.D. (1992). The hypoosmotic swelling test: an update. Arch Androl 29, 105-116.

Jones, R. \& Mann, T. (1977). Damage to ram spermatozoa by peroxidation of endogenous phospholipids. J Reprod Fert 50, 261-268. 
Kadirvel, G., Kathiravan, P. \& Kumar, S. (2011). Protein tyrosine phosphorylation and zona binding ability of in vitro capacitated and cryopreserved buffalo spermatozoa. Theriogenology 75, 1630-1639.

Karabinus, D.S.; Evenson, D.P.; Jost, L.K.; Baer, R.K. \& Kaproth, M.T. (1990). Comparison of semen quality in young and mature Holstein bulls measured by light microscopy and flow cytometry. J Dairy Sci 73, 2364-2371.

Katkov, I.I. \& Lulat, A.G-M.I. (2000). Do conventional CASA-parameters reflect recovery of kinematics after freezing?: "CASA paradox" in the analysis of recovery of spermatozoa after cryopreservation. CryoLetters 21, 141-148.

Kawakami, E.; Kashiwagi, C.; Hori, T. \& Tsutsui, T. (2001). Effects of canine oviduct epithelial cells on movement and capacitation of homologous spermatozoa in vitro. Anim Reprod ScI 68, 121-131.

Kawakami, E.; Morita, Y.; Hori, T. \& Tsutsui, T. (2002). Lectin-binding characteristics and capacitation of canine epididymal spermatozoa. J Vet Med Sci 64, 543-549.

Kawakami, E.; Hori, T. \& Tsutsui, T. (1998). Changes in semen quality and in vitro sperm capacitation during various frequencies of semen collection in dogs with both asthenozoospermia and teratozoospermia. J Vet Med Sci 60, 607-614.

Kawakami, E.; Vandevoort, C.A.; Mahi-Brown, C.A. \& Overstreet, J.W. (1993). Induction of acrosome reactions of canine sperm by homologous zona pellucida. Biol Reprod 48, 841-845.

Kim, S-H., Yu D-H. \& KimY-J. (2010). Effects of cryopreservation on phosphatidylserine translocation, intracellular hydrogen peroxide, and DNA integrity in canine sperm. Theriogenology 73, 282-292.

Kumi-Diaka, J. (1993). Subjecting canine semen to the hype-osmotic teat. Theriogenology 39, 1279-1289.

Lemoine, M.; Grasseau, I.; Brillard, J.P. \& Blesbois, E. (2008). A reappraisal of the factors involved in in vitro initiation of the acrosome reaction in chicken spermatozoa. Reproduction 136, 391-399.

Lewis, S.E. \& Aitken, R.J. (2005). DNA damage to spermatozoa has impacts on fertilization and pregnancy. Cell Tissue Res 322, 33-41.

Liu, D.Y. \& Baker, H.W.G. (1994). A new test for the assessment of sperm-zona pellucida penetration: relationship with results of other sperm tests and fertilization in vitro. Hum Reprod 3, 489-496.

Love, C.C. \& Kenney, R.M. (1998). The relationship of increased susceptibility of sperm DNA to denaturation and fertility in the stallion. Theriogenology, 50, 955-972.

Lucas, X.; Martínez, E.A.; Roca, J.; Vázquez, J.M.; Gil, M.A.; Pastor, L.M. \& Alabart, J.L. (2003). Influence of follicle size on the penetrability of immature pig oocytes for homologous in vitro penetration assay. Theriogenology 60, 659-567.

Łukaszewicz, E.; Jerysz, A.; Partyka, A. \& Siudzińska, A. (2008). Efficacy of evaluation of rooster sperm morphology using different staining methods. Res Vet Sci 85, 583688.

Luvoni, G.C.; Chigioni, S.; Allievi, E. \& Macis, D. (2005). Factors involved in vivo and in vitro maturation of canine oocytes. Theriogenology 63, 41-59.

Madeddu, M.; Berlinguer, F.; Pasciu, V.; Succu, S.; Satta, V.; Leoni, G.G.; Zinellu, A.; Muzzeddu, M.; Carru, C. \& Naitana, S. (2010). Differences in semen freezability 
and intracellular ATP content between the rooster (Gallus gallus domesticus) and the Barbary partridge (Alectoris barbara). Theriogenology 74, 1010-1018.

Maree, L.; du Plessis, S.S.; Menkveld, R. \& van der Horst, G. (2010). Morphometric dimensions of the human sperm head depend on the staining method used. Hum Reprod 25, $1369-1382$.

Martin, G.; Sabido, O.; Durand, P. \& Levy, R. (2004). Cryopreservation induces an apoptosis like mechanism in bull sperm. Biol Reprod 71, 28 -37.

Martin, S.J.; Reutelingsperger, C.P.; McGahon, A.J.; Rader, J.A.; van Schie, R.C.; LaFace, D.M. \& Green, D.R. (1995). Early redistribution of plasma membrane phosphatidylserine is a general feature of apoptosis regardless of the initiating stimulus: inhibition by overexpression of Bcl-2 and Abl. J Exp Med 182, 1545-1556.

Maxwell, W.C.; Catt, S.L. \& Evans, G. (1996). Dose of fresh and frozen-thawed spermatozoa for in vitro fertilization of sheep oocytes. Theriogenology 45, 261.

Maxwell, W.M. \& Johnson, L.A. (1997). Chlortetracycline analysis of boar spermatozoa after incubation, flow cytometric sorting, cooling, or cryopreservation. Mol Reprod Dev 46, 408-418.

Mayenco-Aguirre, A.M. \& Pérez Cortés, A.B. (1998). Preliminary results of hemizona assay (HZA) as a fertility test for canine spermatozoa. Theriogenology 50, 195-204.

Meyers S.A., Yudir A.I., Cherr G.N., VandeVoort C.A., Myles D.G., Primakoff P. \& Overstreet J.W., (1997) Hyaluronidase activity of macaque sperm assessed by in vitro cumulus penetration assay. Mol Reprod Dev 46, 392-400.

Nagy, S.; Hallap, T.; Johannisson, A. \& Rodriguez-Martinez, H. (2004). Changes in plasma membrane and acrosome integrity of frozen-thawed bovine spermatozoa during a $4 \mathrm{~h}$ incubation as measured by multicolor flow cytometry. Anim Reprod Sci 80, 225235.

Neild, D.; Chaves, G.; Flores, M.; Mora, N.; Beconi, M. \& Agüero, A. (1999). Hypoosmotic test in equine spermatozoa. Theriogenology 51, 721-727.

Neild, D.M.; Brouwers, J.F.H.M.; Colenbrander, B.; Aguero, A. \& Gadella, B.M. (2005). Lipid peroxide formation in relation to membrane stability of fresh and frozen thawed stallion spermatozoa. Mol Reprod Dev 72, 230-238.

Niżański, W.; Klimowicz, M.; Partyka, A.; Savić, M. \& Dubiel, A. (2009). Effects of the inclusion of Equex STM into Tris-based extender on the motility of dog spermatozoa incubated at 5 degrees C. Reprod Domest Anim 44, (Suppl. 2), 363-365.

Ortega Ferrusola, C.; Sotillo Galán, Y.; Varela Fernández, E.; Gallardo Bolaños, J.M.; González Fernández, L.; Tapia, J.A. \& Peña, F.J. (2008). Detection of apoptosis like changes during the cryopreservation process in equine sperm. J Androl 29, 213-221.

Ortega-Ferrusola, C.; Macías García, B.; Gallardo-Bolaños, J.M.; González-Fernández, L.; Rodríguez-Martinez, H.; Tapia, J.A. \& Peña, F.J. (2009). Apoptotic markers can be used to forecast the freezeability of stallion spermatozoa. Anim Reprod Sci 114, 393403.

Parks, J.E. \& Graham, J.K. (1992). Effects of cryopreservation procedures on sperm membranes. Theriogenology 38, 209-222.

Partyka, A.; Jerysz, A. \& Pokorny, P. (2007). Lipid peroxidation in fresh and stored semen of Green-legged Partridge. E.J.P.A.U. 10, (2),

http:// www.ejpau.media.pl/volume10/issue2/art-08.html 
Partyka, A.; Łukaszewicz, E. \& Niżański, W. (2011a). Flow cytometric assessment of fresh and frozen-thawed Canada goose (Branta canadensis) semen. Theriogenology 76, 843-850.

Partyka, A.; Łukaszewicz, E.; Niżański, W. \& Twardoń, J. (2011b). Detection of lipid peroxidation in frozen-thawed avian spermatozoa using C11-BODIPY581/591. Theriogenology 75, 1623-1629.

Partyka, A.; Niżański, W. \& Łukaszewicz, E. (2010). Evaluation of fresh and frozen-thawed fowl semen by flow cytometry. Theriogenology 74, 1019-1027.

Peña Martínez, A.I. (2004). Canine fresh and cryopreserved semen evaluation. Anim Reprod Sci 82-83, 209-224.

Peña, A.I.; Johannisson, A. \& Linde-Forsberg, C. (2001). Validation of flow cytometry for assessment of viability and acrosomal integrity of dog spermatozoa and for evaluation of different methods of cryopreservation. J Reprod Fertil (Suppl. 57), 371376.

Peña, A.I.; Quintela, L.A. \& Herradón, P.G. (1998). Viability assessment of dog spermatozoa using flow cytometry. Theriogenology 50, 1211-1220.

Pena, F.J.; Johannisson, A.; Wallgren, M. \& Rodriguez-Martinez, H. (2003). Assessment of fresh and frozen-thawed boar semen using an Annexin-V assay: a new method of evaluating sperm membrane integrity. Theriogenology 60, 677-689.

Pérez-Llano, B.; Lorenzo, J.L.; Yenes, P.; Trejo, A. \& Garcia-Casado, P. (2001). A short hypoosmotic swelling test for the prediction of boar sperm fertility. Theriogenology 56, 387-398.

Petrunkina, A.M.; Simon, K.; Günzel-Apel, A.R. \& Töpfer-Petersen, E. (2003). Regulation of capacitation of canine spermatozoa during co-culture with heterologous oviductal epithelial cells. Reprod Domest Anim 38, 455-463.

Petrunkina, A.M.; Simon, K.; Günzel-Apel, A.R. \& Töpfer-Petersen, E. (2004). Kinetics of protein tyrosine phosphorylation in sperm selected by binding to homologous and heterologous oviductal explants: how specific is the regulation by the oviduct? Theriogenology 61, 1617-1634.

Ramos, L. \& Wetzels, A.M. (2001). Low rates of DNA fragmentation in selected motile human spermatozoa assessed by the TUNEL assay. Hum Reprod 16, 703-707.

Rathi, R.; Colenbrander, B.; Bevers, M.M. \& Gadella, B.M. (2001). Evaluation of in vitro capacitation of stallion spermatozoa. Biol Reprod 65, 462-470.

Rijsselaere, T.; Van Soom, A.; Hoflack, G.; Maes, D. \& de Kruif, A. (2004). Automated sperm morphometry and morphology analysis of canine semen by the Hamilton-Thorne analyser. Theriogenology 62, 1292-1306.

Rijsselaere, T.; van Soom, A.; Maes, D. \& de Kruif, A. (2003). Effect of technical settings on canine semen motility parameters measured by the Hamilton-Thorne analyzer, Theriogenology 60, 1553-1568.

Rijsselaere, T.; Van Soom, A.; Tanghe, S.; Coryn, M.; Maes, D. \& de Kruif, A. (2005). New techniques for the assessment of canine semen quality: A review. Theriogenology 64, 706-719.

Rodríguez-Gil, J.E.; Montserrat, A. \& Rigau, T. (1994). Effects of hypoosmotic incubation on acrosome and tail structure on canine spermatozoa. Theriogenology 42, 815-829.

Rota, A.; Peña, A.I.; Linde-Forsberg, C. \& Rodriguez-Martinez, H. (1999). In vitro capacitation of fresh, chilled and frozen-thawed dog spermatozoa assessed by the 
chloretetracycline assay and changes in motility patterns. Anim Reprod Sci 57, 199215.

Rubio-Guillén, J.; González, D.; Garde, J.J.; Esteso, M.C.; Fernández-Santos, M.R.; Rodríguez-Gíl, J.E.; Madrid-Bury, N. \& Quintero-Moreno, A. (2007). Effects of cryopreservation on bull spermatozoa distribution in morphometrically distinct subpopulations. Reprod Domest Anim 42, 354 -357.

Saint-Dizier, M.; Salomon J.F.; Petit C.; Renard J.P. \& Chastant-Maillard S. (2001). In vitro maturation of bitch oocytes: effect of sperm penetration. J Reprod Fertil (Suppl. 57), 147-150.

Santiago-Moreno, J.; Castano, C.; Coloma, M.A.; Gomez-Brunet, A.; Toledano-Diaz, A.; Lopez-Sebastian, A. \& Campo, J.L. (2009). Use of the hypo-osmotic swelling test and aniline blue staining to improve the evaluation of seasonal sperm variation in native Spanish free-range poultry. Poult Sci 88, 2661-2669.

Silva, P.F. \& Gadella, B.M. (2006). Detection of damage in mammalian sperm cells. Theriogenology 65, 958-978.

Sirivaidyapong, S., Cheng F.P., Marks A., Voorhout W.F., Bevers M.M. \& Colenbrander B. (2000). Effect of sperm diluents on the acrosome reaction in canine sperm. Theriogenology 53, 789-802.

Sprecher, D.J. \& Coe, P.H. (1996). Differences in bull spermiograms using eosin-nigrosin stain, feulgen stain, and phase contrast microscopy methods. Theriogenology $45,757-$ 764.

Suarez S.S., Katz D.F. \& Overstreet J.W. (1983). Movement characteristics and acrosomal status of rabbit spermatozoa recovered at the site and time of fertilization. Biol Reprod 29, 1277-87.

Szász, F.; Sirivaidyapong, S.; Cheng, F.P.; Voorhout, W.F.; Marks, A.; Colenbrander, B.; Solti, A.L. \& Gadella, B.M. (2000). Detection of calcium ionophore induced membrane changes in dog sperm as a simple method to predict the cryopreservability of dog semen. Mol Reprod Dev 55, 289-298.

Talbot, P. \& Chacon, R.S. (1981). A triple-stain technique for evaluating normal acrosome reactions of human sperm. J Exp Zool 215, 201-208.

Thuwanut, P.; Axner, E.; Johanisson, A. \& Chatdarong K. (2009). Detection of lipid peroxidation reaction in frozen-thawed epididymal cat spermatozoa using BODIPY 581/591 C11. Reprod Dom Anim 44, (Suppl. 2), 373-376.

van der Venn, H.H.; Jeyendran, R.S.; Al-Hasani, S.; Pérez-Pelàez, M.; Diedrich, K. \& Zaneveld, L.J.D. (1986). Correlation between human sperm swelling in hypoosmotic medium (hypoosmotic swelling test) and in vitro fertilisation. J Androl 7, 190-196.

Vazquez, J.M.; Martinez, E.A.; Martinez, P.; Garcia-Artiga, C. \& Roca, J. (1997). Hypoosmotic swelling of boar spermatozoa compared to other methods for analysing the sperm membrane. Theriogenology 47, 913-922.

Verstegen, J.; Iguer-ouada, M. \& Onclin K. (2002). Computer assisted semen analyzers in andrology research and veterinary practice. Theriogenology 57, 149-179.

Watson, P.F. (1995). Recent developments and concepts in the cryopreservation of spermatozoa and assessment of their post-thawing function. Reprod Fertil Dev 7, 871-891. 
World Health Organization. (2010). WHO laboratory manual for the examination and processing of human semen. 5th ed. WHO Press.

Yanagimachi, R.; Yanagimachi, H. \& Rogers, B.J. (1976). The use of zona-free animal ova as a test system for the assessment of the fertilizing capacity of human spermatozoa. Biol Reprod 15, 471-476.

Zambelli, D. \& Cunto, M. (2006). Semen collection in cats: techniques and analysis. Theriogenology 66, 159-165. 


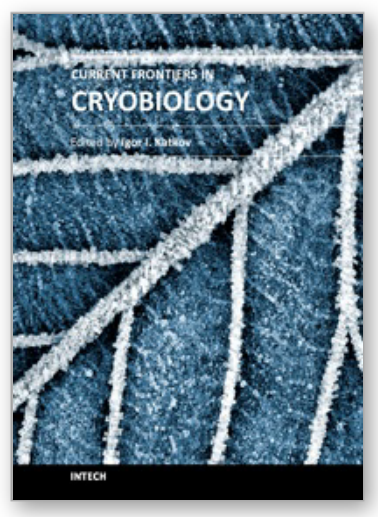

\section{Current Frontiers in Cryobiology}

Edited by Prof. Igor Katkov

ISBN 978-953-51-0191-8

Hard cover, 574 pages

Publisher InTech

Published online 09, March, 2012

Published in print edition March, 2012

Almost a decade has passed since the last textbook on the science of cryobiology, Life in the Frozen State, was published. Recently, there have been some serious tectonic shifts in cryobiology which were perhaps not seen on the surface but will have a profound effect on both the future of cryobiology and the development of new cryopreservation methods. We feel that it is time to revise the previous paradigms and dogmas, discuss the conceptually new cryobiological ideas, and introduce the recently emerged practical protocols for cryopreservation. The present books, "Current Frontiers in Cryobiology" and "Current Frontiers in Cryopreservation" will serve the purpose. This is a global effort by scientists from 27 countries from all continents and we hope it will be interesting to a wide audience.

\section{How to reference}

In order to correctly reference this scholarly work, feel free to copy and paste the following:

Agnieszka Partyka, Wojciech Niżański and Małgorzata Ochota (2012). Methods of Assessment of Cryopreserved Semen, Current Frontiers in Cryobiology, Prof. Igor Katkov (Ed.), ISBN: 978-953-51-0191-8, InTech, Available from: http://www.intechopen.com/books/current-frontiers-in-cryobiology/methods-ofassessment-of-cryopreserved-semen

\section{INTECH}

open science | open minds

\section{InTech Europe}

University Campus STeP Ri

Slavka Krautzeka 83/A

51000 Rijeka, Croatia

Phone: +385 (51) 770447

Fax: +385 (51) 686166

www.intechopen.com

\section{InTech China}

Unit 405, Office Block, Hotel Equatorial Shanghai

No.65, Yan An Road (West), Shanghai, 200040, China

中国上海市延安西路65号上海国际贵都大饭店办公楼 405 单元

Phone: +86-21-62489820

Fax: +86-21-62489821 
(C) 2012 The Author(s). Licensee IntechOpen. This is an open access article distributed under the terms of the Creative Commons Attribution 3.0 License, which permits unrestricted use, distribution, and reproduction in any medium, provided the original work is properly cited. 